\title{
Elaborative Inference in Children with Poor Reading Comprehension: Instrument Inference
}

\author{
Ye Seul Park ${ }^{\mathrm{a}}$, Mina Hwang ${ }^{\mathrm{b}}$, Sunhee Ko \\ ${ }^{a}$ Graduate School of Special Education, Dankook University, Yongin, Korea \\ ${ }^{b}$ Department of Special Education, Dankook University, Yongin, Korea \\ 'Department of Speech-Language Pathology, Graduate School, Dankook University, Yongin, Korea
}

Correspondence: Sunhee Ko, $\mathrm{PhD}$

Department of Speech-Language Pathology, Graduate School, Dankook University, 152 Jukjeon-ro, Suji-gu, Yongin 16890, Korea Tel: +1-224-723-4528

Fax: +1-847-941-8830

E-mail: sun7610@hanmail.net

Received: October 4, 2017

Revised: November 2, 2017

Accepted: November 8, 2017

\begin{abstract}
Objectives: Elaborative inference is the integration of a text and the reader's knowledge; it facilitates comprehension and allows readers to more easily learn the information contained within the text. The purpose of this study was to investigate characteristics of instrument inference (a type of elaborative inference) in poor comprehenders. Methods: The participants were 15 poor comprehenders and 15 normally developing children in 3rd to 6th grade. The children were asked to decide if target words (instrument words) were words or nonwords after reading sentences including the cue to infer instrument while measuring their reaction time. In this lexical decision task, the target words were divided into two conditions: the related condition between sentences and instruments words (related condition) and the unrelated condition between sentences and instrument words (unrelated condition). Results: Normally developing children reacted faster in the related condition than the unrelated condition; on the other hand, poor comprehenders showed no significant difference between the two conditions. Conclusion: Unlike normally developing children, poor comprehenders failed to infer instruments in real time while reading. From this result, it can be explained that poor comprehenders have difficulty in processing implicit information while reading texts because they assign most of their comprehension resources to processing the literal information in the text.
\end{abstract}

Keywords: Poor comprehenders, Instrument inference, Lexical decision task
읽기는 단순한 관점에서 보면 글자를 소리 내어 읽는 음독 능력 을 일컫기도 하지만 더 나아가서는 단어, 문장, 담화가 담고 있는 정 보를 이해하는 능력까지를 포함한다(Catts, Adlof, \& Weismer, 2006). 음독은 일반적으로 읽기 이해보다 일찍 습득되며, 대부분의 아동들이 초등학교 저학년 시기에 완전히 습득하는 능력이다. 그 러나 아동들이 음독을 정확히 했다 할지라도 그 내용에 대한 이해 정도는 아동들마다 차이가 있을 수 있으며, 특히 음독에는 문제가 없지만 그 내용을 이해하는 데 현저하게 어려움을 보이는 경우를 읽기이해부진(poor comprehender)이라 칭한다(Cain \& Oakhill, 2007).

학령기 아동들에게 있어 읽기 이해는 교과 내용을 습득하기 위 하여 반드시 전제되어야 하는 능력이며, 아동들은 읽기를 통해 새 로운 지식을 빠르게 확장해 간다(Jeong, 2009). 그러나 고학년으로
갈수록 읽어야 하는 정보의 양이 많아지고, 사용되는 문장 역시 길 고 복잡해지기 때문에 읽기이해부진 아동들의 경우 읽기 이해의 어려움이 더욱 두드러질 수 있다(Cain \& Oakhill, 2007). 그렇기에 본 연구에서는 학령기 읽기이해부진 아동들을 대상으로 이들의 읽 기 이해 특성을 살펴보고자 하였다.

성공적인 읽기 이해를 위해서는 문자적인 정보를 이해하는 데 그치는 것이 아니라 직접적으로 글에 언급되어 있지는 않지만 그 정보들과 관련된 내용들까지 추론하는 능력이 필요하다. 글을 읽 는 사람은 정보들 간의 응집성을 높이고 글에서 제시된 정보와 개 인이 가지고 있는 사전 지식을 통합함으로써 글의 표상을 정교화 하게 되는데(Lee \& Lee, 1997), 이 같은 추론 과정은 글을 종합적으 로 이해할 수 있도록 촉진할 뿐만 아니라 읽은 내용을 기억하고 학 습하는 데도 도움을 준다(Jo et al., 2003; Stein et al., 1982). 
읽기 이해를 위해 추론 능력이 핵심적인 역할을 한다고 볼 때, 읽 기이해부진 아동들이 읽기 이해에 어려움을 보이는 것을 그들의 추론 능력과 연결지어 생각해볼 수 있다. 여러 연구들에서 보면 제 시된 글의 길이나 내용의 복잡성에 따라 다소 차이가 있기는 하지 만, 일반적으로 읽기이해부진 아동들이 읽은 내용을 기억하는 데 비교적 양호한 수행을 보이는 데 반해 문장들 간의 의미를 연결하 면서 그 내용들을 통합한다거나 읽은 내용과 배경 지식을 연결시 킴으로써 그 의미를 해석하는 추론 능력은 일반 아동들에 비해 저 조한 것으로 보고되고 있다(Bowyer-Crane \& Snowling, 2005; Cain \& Oakhill, 2007; Jang \& Lee, 2016; Jeong, 2013). 그러나 이 같은 연 구들은 글을 읽은 후에 아동들에게 관련된 질문을 하고 이에 답하 도록 하는 방식으로 읽기이해부진 아동들의 추론 능력을 평가하였 기 때문에, 이들이 추론에 어려움을 보인다 할지라도 글을 읽는 중 에 실시간으로 추론을 하는 데 어려움이 있는 것인지 아니면 글을 읽은 후에 기억한 정보를 바탕으로 추론하는 데 어려움이 있는 것 인지에 대해 결론을 내리기에는 어려움이 있다. 따라서, 본 연구에 서 정교화 추론의 한 형태인 도구 추론을 중심으로 읽기이해부진 아동들이 글을 읽는 중에 실시간(on-line)으로 관련 정보를 추론 을 하는 것이 가능한지를 알아보고자 하였다.

도구 추론이란 문장 내 ‘목적어+동사’의 관계로부터 동사의 행위 를 위한 구체적인 도구를 추론하는 것을 말한다(Jo \& Lee, 1997). 예를 들어 '미용사가 손님의 머리를 잘랐다’라는 문장을 읽을 경우 문장에서는 무엇으로 머리를 잘랐는지에 대한 정보가 언급되어 있 지는 않지만 '가위'라는 도구가 사용되었을 것이라고 추론할 수 있 다. 선행연구들에서 도구 추론과 같은 정교화 추론은 글을 읽는 동 안에 실시간으로 생성된다는 결과들을 보여주고 있으며(Lee \& Lee, 1999; Lee, Lee, Kim, \& Lee, 1997), 읽기 발달 수준이나작업기 억 능력에 따라 개인차가 있을 수 있다고 하였다(Kim \& Yoo, 2001; Lee et al., 1997; Paris \& Lindauer, 1976).

이에 본 연구에서는 읽기이해부진 아동의 추론 특성을 살펴보 고자 어휘판단과제(lexical decision task)를 사용하였다. 어휘판단 과제는 문장을 읽는 과정에서 실시간으로 추론이 생성되는지를 알 아볼 수 있다는 장점이 있으며 선행연구에서도 이를 위해 종종 사 용되었던 과제이다(Kim \& Yoo, 2001; Lee \& Lee, 1999; Lee et al., 1997; Lucas, Tanenhaus, \& Carlson, 1990). 이 과제는 아동들에게 도구 추론이 가능한 유도 문장(예: 선생님이 교실에 들어와 벽에 못 을 박았다)을 읽게 한 후 곧바로 제시되는 목표 단어(예: 망치 또는 수건)가 단어인지 아닌지를 판단하도록 하여 그 반응시간을 측정 하게 된다. 이때, 유도 문장 직후에 제시되는 목표 단어가 유도 문장 에서 추론이 가능한 단어(예: 망치)라면 유도 문장과 관련이 없는
단어(예: 수건)에 비해 그 단어가 단어임을 더 빠르게 판단할 수 있 을 것이고, 결과적으로 이때의 반응시간은 문장을 읽는 중에 도구 단어의 활성화 수준을 의미하게 된다. 앞서 살펴본 바와 같이 읽기 이해부진 아동들은 추론에 어려움을 보이기 때문에 어휘판단과제 를 실시하였을 때 일반 아동들과는 다른 반응 양상을 보일 것으로 예상할수 있다.

지금까지 고찰한 내용들을 토대로, 본 연구에서는 읽기이해부진 아동들이 문장을 읽으면서 실시간으로 추론을 생성하는지 여부를 확인하는 것을 목적으로 하였으며, 이를 위해 도구 추론이 가능한 문장을 읽고 그 직후에 제시되는 목표 단어가 단어인지를 아닌지 를 판단하도록 하는 어휘판단과제를 실시하여 읽기이해부진 아동 들과 일반 아동들이 그 반응시간에 있어 차이를 보이는지 알아보 았다.

\section{연구방법}

\section{연구대상}

연구대상은 경기 지역 초등학교에 재학 중인 3-6학년 읽기이해 부진 아동 15 명, 일반 아동 15 명으로 총 30 명이었다. 읽기이해부진 아동의 선정 기준은 다음과 같다. (1) 지역아동센터에서 담당 사회 복지사에 의해 읽기 이해에 어려움이 있는 것으로 보고된 아동들 을 대상으로, (2) 기초학력검사(Korea Institute for Special Education-Basic Academic Achievement Test, KISE-BATT; Park, Kim, Song, Jung, \& Jung, 2008) 결과 음독(읽기I)에서는 $25 \%$ ile 이상이 고, (3) 독해(읽기II)에서는 $25 \%$ ile 이하에 속하는 아동이며, (4) 한 국판 웩슬러 아동 지능검사(Korean version Wechsler Intelligence Scale for Children, K-WISC-III; Kwak, Park, \& Kim, 2001) 결과 동 작성 지능이 85 이상이고, (5) 기질적 장애, 정서 및 행동장애, 감각 장애가 없는 아동으로 선정하였다. 일반 아동의 선정 기준은 다음 과 같다. (1) 지역아동센터에서 담당 사회복지사에 의해 읽기이해에 어려움이 없는 것으로 보고된 아동들을 대상으로, (2) 기초학력검 사(KISE-BATT; Park et al., 2008) 결과 음독(읽기I)과 독해(읽기II) 에서 25\%ile 이상에 속하는 아동이며, (3) 한국판 웩슬러 아동 지능 검사(K-WISC- III; Kwak et al., 2001) 결과 동작성 지능이 85 이상 이고, (4) 기질적 장애, 정서 및 행동장애, 감각장애가 없는 아동으 로 선정하였다.

읽기이해부진 아동 집단과 일반 아동 집단 간 연령, 동작성 지능, 음독 및 독해 능력에서 차이가 있는지를 확인하기 위해 $t$-검정을 실 시한 결과, 연령, 동작성 지능, 음독에서는 집단 간 유의미한차이가 나타나지 않았고, 독해에서만 통계적으로 유의한 차이가 나타났다 
Table 1. Participants' characteristics

\begin{tabular}{lccc}
\hline Characteristic & $\begin{array}{c}\text { Poor compre- } \\
\text { henders }(\mathrm{N}=15)\end{array}$ & $\begin{array}{c}\text { Good compre- } \\
\text { henders }(\mathrm{N}=15)\end{array}$ & $t$ \\
\hline Age $(\mathrm{yr})$ & $9.9(11.03)$ & $10.37(8.00)$ & 1.610 \\
${\text { Performance } 1 \mathrm{O}^{\mathrm{a}}}_{\text {Decoding }(\% \text { ile) }}^{\mathrm{b}}$ & $100.86(12.98)$ & $100.40(9.33)$ & -.113 \\
Text comprehension $\left(\%\right.$ ile) $^{b}$ & $98.40(3.85)$ & $99.86(0.51)$ & 1.462 \\
\hline
\end{tabular}

Values are presented as mean (SD).

${ }^{a}$ K-WISC-III (Korean Wechsler Intelligence Scale for Children-III; Kwak, Park, \& Kim, 2001). ' 'KISE-BATT (Korea Institute for Special Education-Basic Academic Achievement Test; Park, Kim, Song, Jung, \& Jung, 2008). ${ }^{*} p<.001$.

$(t=24.679, p<.001)$. 연구대상에 대한 자세한 정보는 Table 1과 같다.

\section{연구도구}

본 연구에서는 아동들의 도구 추론 능력을 알아보기 위하여 어 휘판단과제를 사용하였다. 이 과제는 유도 문장을 읽은 후 그 직후 에 제시되는 단어의 형태가 단어인지 비단어인지를 '예/아니오'로 판단하는 과제이다. 이때, 유도 문장은 특정 도구를 추론할 수 있는 단서를 포함하고 있으며, 목표 단어는 유도 문장과 관련된 도구가 제시되는 조건(이하 관련 조건)과 유도 문장과 관련이 없는 도구가 제시되는 조건(이하 무관련 조건)으로 나뉘어진다. 비단어가 제시 되어 아동들이 '아니오'로 판단한 문항들은 채우기 문항으로 활용 되었다.

유도 문장과 관련이 있는 목표 도구 단어를 선정하기 위하여 언 어병리학과 석사과정 대학원생 30 명에게 사전 검사를 실시하였다. 사전 검사는 도구가 생략된 32 개의 문장을 주고 가장 먼저 떠오르 는 도구를 빈칸에 적도록 하였다. 예를 들어 '할머니가 과일을 씻어 서 껍질을

(으)로 깎았다'라는 문장의 빈칸에 가장 적절하 다고 생각하는 단어를 적도록 하였다. 사전 검사 결과 일관되게 한 가지 도구 단어가 생성된 문장들을 중심으로 본 실험의 유도 문장 과 목표 단어로 사용하였다. 유도 문장은 5-6어절, 15-17음절, 복문 으로 이루어져 있으며, 유도 문장의 첫 번째 절에는 도구 단어를 추 론 할 수 있는 단서가 포함되어 있지 않고 두 번째 절에는 목표 도구 단어에 대한 단서가 포함되도록 제작하였다(예: '할머니가 과일을 씻어 껍질을 깎았다'). 관련 조건과 무관련 조건의 목표 단어는 1-3 음절의 도구가 될 수 있는 명사를 사용하였다(예: '칼', '풀').

본 과제를 제작하기 위해서 사용된 단어들은 Kim (2003)의 등 급별 국어 교육용 어휘를 참고하였을 때 4 등급 어휘인 2 개의 단어 를 제외한 모든 어휘가 1-3등급 어휘에 해당된다. 또한, 초등학교 3-6학년 학생 40명에게 유도 문장과 목표 단어에 사용된 어휘들에 대하여 5점 척도로 친숙도 검사를 하였을 때 평균 4.4점 이상이었
고, 4등급으로 분류된 어휘인 ‘물개’와 ‘박스’ 역시 친숙도가 높게 나 타났다.

본 과제에 사용된 비단어는 현대 국어 사용 빈도(National Institute of the Korean Language, 2005)가 500 이상인 1-3음절 단어 중 임의로 선정한 후 단어의 모음들을 변경하여 제작하였다. 단모음 의 경우는 '아 $\leftrightarrow$ 어, 오 $\leftrightarrow$ 우, 으 $\leftrightarrow$ 오, 이 $\leftrightarrow$ 애'를 기본 규칙으로 하였 고(예: 강물 $\rightarrow$ 겅몰), 이중모음의 경우에는 두 개의 모음 조합 중 하 나의 모음만 변경하거나 단모음화 하여 변경하였다(예: 윅ㅇㅇ, 교 $\rightarrow$ 고). 1 음절의 비단어를 만들기 위해서는 기존 단어의 모음을 이중 모음으로 변경하거나 초성을 변경하였다(예: 감 $\rightarrow$ 걈, 성ㄱ렁).

이 같은 과정을 거쳐 최종적으로 본 문항 42 개, 연습 문항 8 개를 제작하였다. 42 개의 유도 문장 중 28 개는 관련 조건의 도구 단어와 무관련 조건의 도구 단어와 각각 짝을 이루도록 하였고, 나머지 14 개의 유도 문장은 비단어와 짝을 이루도록 하였다. 한 아동이 유도 문장을 반복하여 보지 않도록 하기 위하여 문항을 $\mathrm{A}, \mathrm{B}$ 세트로 나 누어 배치하였는데 각 세트에는 관련 조건 14 문항, 무관련 조건 14 문항, 비단어 조건 14 문항씩, 총 42 문항으로 구성되어 있다. 각 세트 내에서 문항들이 제시될 때 무작위로 제시되더라도 동일한 조건이 연속하여 3 회 이상 제시되거나 어휘판단에서 동일한 반응이 3 회 이상 반복되지 않도록 조정하였다. 본 실험에 사용된 유도 문장과 목표 단어 예시는 Appendix 1과 같다.

본 과제를 통해 결과를 얻기 위해서는 아동들이 유도 문장을 성 실하게 읽고 그 의미를 처리하는 것이 전제되어야 한다. 어휘판단과 제의 특성상 같은 형식의 문항들이 반복적으로 제시되고, 실제로 아동들은 목표 단어에 대해서만 단어인지 아닌지를 반응하면 되기 때문에 일부 아동들의 경우 유도 문장을 무시한 채 목표 단어에만 집중하여 반응하는 전략을 사용할 수 있다. 이를 방지하고 아동들 이 유도 문장을 성실하게 읽도록 유도하기 위해 각 세트 내에 절반 인 21개의 문항에 대해서는 어휘판단이 끝난 직후 유도 문장에 포 함된 문자 정보를 묻는 질문을 하여 이에 ‘예/아니오'로 답하도록 하였다.

\section{연구절차}

아동들이 본 과제를 정확히 이해할 수 있도록 설명을 제공하기 위하여 파워포인트로 제작된 시각적인 자료를 사용하였다. 검사자 는 과제가 어떻게 진행되는지, 아동들이 어떻게 반응해야 하는지 를 가상으로 보여주면서 설명하였고, 이때 가능한 빠르고 정확하 게 반응해야 한다는 주의사항을 강조하여 전달하였다. 아동이 과 제에 대해 충분히 이해한 것으로 판단된 경우, 8 개의 연습 문항을 실시하였고, 만약 아동이 실험 방법과 조작에 어려움을 보일 경우 


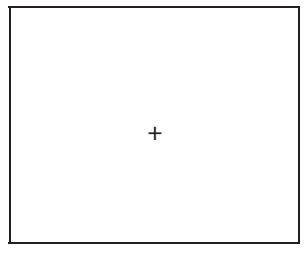

(500 ms)

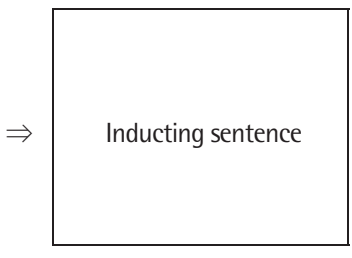

(Space bar)

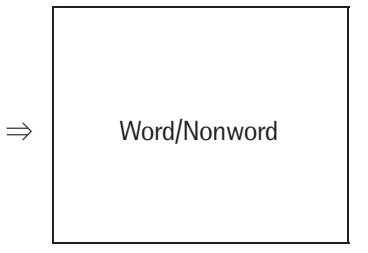

(Yes/No)

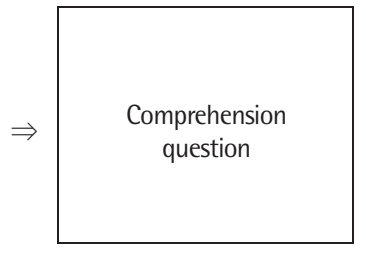

(Yes/No)

Figure 1. Process of lexical decision task.

에는 연습 문항을 반복하여 실시한 후 본 과제를 실시하였다.

본 과제는 E-Prime을 사용하여 제작하였고, 실험은 개인용 노트 북(LG gram 15Z960 i5)을 이용하여 실시하였다. 자극은 하얀 바탕 에 검정색, 굴림체, 글자 크기 38 point로 화면 중앙에 제시되었다. 모니터 화면 중앙에 응시점(+) 표시가 $500 \mathrm{~ms}$ 동안 나타났다 사라 지면 같은 위치에 유도 문장이 한 줄로 제시되었다. 아동들이 유도 문장을 읽자마자 왼손으로 SPACE BAR를 누르면 즉시 문장이 사 라지고 목표 단어가 나타나는데 제시된 글자가 단어이면 마우스의 왼쪽 버튼을 눌러 ‘예' 반응을 하도록 하였고, 단어가 아니면 마우 스 오른쪽 버튼을 눌러 '아니오' 반응을 하도록 하였다. 어휘판단 후 이해 질문이 제시되면 아동은 앞서 읽은 유도 문장과 질문의 내 용이 일치하면 ‘예' 버튼을, 일치하지 않으면 ‘아니오' 버튼을 누르 도록 하였다. 마우스 왼쪽과 오른쪽에는 예, 아니오 글자를 붙여 아 동들이 혼동하지 않고 정확하게 누를 수 있도록 표시하였고, 아동 들의 모든 반응은 프로그램 내에서 자동으로 기록되었다. 아동 한 명당 약 15 분의 시간이 소요되었다(Figure 1).

\section{자료분석}

목표 단어가 제시되었을 때 아동들이 ‘예’라고 판단한 문항들에 대해 관련 조건과 무관련 조건 각각에 대한 반응시간을 측정하여 분석하였고, 비단어가 제시되어 아동들이 '아니오'로 판단한 문항 들은 채우기 문항으로 활용된 것이기에 별도로 분석에 포함되지 않았다.

어휘판단과제에 대한 어휘판단 정확도 및 이해 질문에 대한 정확 도에 있어 읽기이해부진 아동과 일반 아동 간에 차이가 있는지를 알아보고자 독립표본 $t$-검정을 실시하였고, 읽기이해부진 아동과 일반 아동 간 관련과 무관련 조건에 따른 어휘판단 반응시간에 차 이가 있는지를 알아보기 위하여 반복측정 이원분산분석(two-way ANOVA)을 실시하였다.

수집된 데이터는 SPSS Window 22.0 (IBM SPSS Statistics Data Editor) 통계프로그램을 사용하여 분석하였다.

\section{연구결과}

어휘판단과제의 결과 분석에 앞서 어휘판단과제에 포함되어 있 는 이해 질문에 대한 정확도를 분석하였는데 읽기이해부진 아동은 평균 18.93 (2.40)점, 일반 아동은 평균 18.80 (1.78)점이었다. 이해질 문에 대한 정확도에 있어도 집단 간 차이가 있는지를 알아보기 위 해 $t$-검정을 실시한 결과 통계적으로 유의한 차이를 보이지 않았다. 이 같은 결과로 보아 읽기이해부진 아동들이 유도 문장 내에 포함 되어 있는 정보를 기억하는 데는 일반 아동들과 차이가 없었음을 알수 있다.

또한, 읽기이해부진 아동들이 단어와 비단어를 판단하는 데 있 어 일반 아동들에 비해 어려움이 있었는지를 알아보기 위해 어휘 판단 정확도를 분석하였다. 총점 42 점에 대하여 읽기이해부진 아 동 집단은 평균 40.80 (1.47)점, 일반 아동 집단은 평균 41.40 (1.12) 점으로 $t$-검정을 실시한 결과 어휘판단 정확도에 있어 두 집단 간 유의한차이가 없는 것으로 나타났다.

마지막으로, 두 집단의 유도 문장과 목표 단어의 관련 조건에 따 른 어휘판단 반응시간을 분석하였다. 읽기이해부진 아동은 관련 조건에서 1,251.58 (170.76) ms, 무관련 조건에서 1,226.14 (175.41) $\mathrm{ms}$ 으로 두 조건 간 반응시간의 차이가 $25.44 \mathrm{~ms}$ 이었고, 일반 아동 은 관련 조건에서 1,008.21 (171.62) ms, 무관련 조건에서 1,212.88 (197.26) ms으로 두 조건 간 반응시간의 차이가 - $204.67 \mathrm{~ms}$ 이었다. 이같은 결과로 보아 읽기이해부진 아동의 경우는 조건 간에 반응 시간에 있어 크게 차이가 없었던 데 반면 일반 아동의 경우는 무관 련 조건에서보다 관련 조건에서 반응시간이 빨랐음을 알 수 있다. 읽기이해부진 아동과 일반 아동의 어휘판단과제의 반응시간에 대 한 기술통계 결과는 Table 2 와 같다.

어휘판단과제에서 읽기이해부진 아동과 일반 아동이 관련 조건 과 무관련 조건에 따른 어휘판단 반응시간에 있어 차이가 있었는 지를 알아보기 위하여 반복측정 이원분산분석을 실시하였다(Table 3). 그 결과, 집단 간 주효과 $\left(F_{(1,28)}=4.308, p<.05\right)$, 조건 간 주효 과 $\left(F_{(1,28)}=17.665, p<.001\right)$ 가 유의하였으며, 집단과 조건 간 상호작 
Table 2. Result of descriptive statistics on reaction time on lexical decision task

\begin{tabular}{lccc}
\hline & $\mathrm{RC}(\mathrm{N}=15)$ & $\mathrm{UC}(\mathrm{N}=15)$ & $t$ \\
\hline Poor comprehenders (ms) & $1,251.58(170.76)$ & $1,226.14(175.41)$ & 1.231 \\
Good comprehenders (ms) & $1,008.21(171.62)$ & $1,212.88(197.26)$ & $-5.486^{* * *}$
\end{tabular}

Values are presented as mean (SD).

$\mathrm{RC}=$ related condition; $\mathrm{UC}=$ unrelated condition .

${ }^{* * *} p<.001$.

용 효과 역시 유의한 것으로 나타났다 $\left(F_{(1,28)}=29.118, p<.001\right)$. 이 는 일반 아동의 경우에는 읽기이해부진 아동과 달리 유도 문장과 목표 단어의 관련성 여부가 어휘판단 속도에 영향을 미쳤음을 의 미한다.

집단과 조건의 상호작용 효과를 확인하기 위하여 집단별로 관련 조건과 무관련 조건에 따른 반응시간에 대한 $t$-검정을 실시하였다. 그 결과, 읽기이해부진 아동은 두 조건 간에 유의한 차이가 나타나 지 않았지만, 일반 아동들은 두 조건 간 유의한 차이가 나타났다 $(t=-5.486, p<.001)$. 이는 일반 아동은 유도 문장과 목표 단어가 서 로 관련이 있을 경우 그렇지 않을 때보다 목표 단어의 단어 여부를 빠르게 판단한 데 비해 읽기이해부진 아동은 유도 문장과 목표 단어 의 관련성 여부와상관없이 유사한 반응시간을 보였음을 알 수 있다.

\section{논의 및 결론}

본 연구는 3-6학년 읽기이해부진 아동들을 대상으로 그들의 추 론 처리 특성을 알아보고자 하였으며, 이를 위해 어휘판단과제를 실시하여 어휘판단에 대한 반응시간, 어휘판단 정확도, 그리고 이 해 정확도를 분석하였다.

어휘판단 반응시간에 대한 결과를 살펴보기에 앞서 읽기이해부 진 아동과 일반 아동의 어휘판단 정확도와 읽기 이해 정확도를 분 석하였다. 읽기이해부진 아동과 일반 아동 모두 어휘판단 정확도 와 읽기 이해 정확도에서 만점에 가까운 점수를 얻었고, 두 집단 간 에 유의한 차이가 없는 것으로 나타났다. 이 같은 결과로 보아 일반 아동뿐 아니라 읽기이해부진 아동 역시 목표 단어를 보고 단어임 을 판단하는 데 어려움이 없었음을 확인할 수 있으며, 읽기이해부 진 아동 역시 일반 아동들처럼 유도 문장을 성실하게 읽었고 그 정 보를 기억하는 데 어려움이 없었음을 알 수 있다.

본 연구에서는 유도 문장을 읽은 후 직후에 나타나는 목표 단어 가 단어인지를 판단하도록 하여 반응시간을 측정하였는데 이때 목 표 단어는 유도 문장에서 추론 가능한 도구 명사인 경우와 유도 문 장과는 관련 없는 도구 명사인 경우로 나뉘었다. 이 어휘판단과제 에서 읽기이해부진 아동들은 관련 조건과 무관련 조건에서 모두
Table 3. Result of two-way ANOVA

\begin{tabular}{lrrrrr}
\hline Source & $\begin{array}{c}\text { Type III sum of } \\
\text { squares }\end{array}$ & $d f$ & $\begin{array}{c}\text { Mean } \\
\text { square }\end{array}$ & $F$ & $p$-value \\
\hline Between group & & & & & \\
$\quad$ Group & $246,966.83$ & 1 & $246,966.83$ & 4.31 & $.047^{*}$ \\
$\quad$ Error & $1,605,264.10$ & 28 & $57,330.86$ & & \\
Within group & & & & & \\
$\quad$ Condition & $120,456.79$ & 1 & $120,456.79$ & 17.67 & $.000^{* * *}$ \\
$\quad$ Condition×Group & $198,552.23$ & 1 & $198,552.24$ & 29.12 & $.000^{* * *}$ \\
$\quad$ Error & $190,927.79$ & 28 & $6,818.86$ & & \\
\hline
\end{tabular}

${ }^{*} p<.05,{ }^{* * *} p<.001$

비슷한 반응시간을 보인 반면 일반 아동들의 경우에는 무관련 조 건에서보다 관련 조건에서 유의미하게 빠른 반응시간을 보였다. 이 같은 결과에 대해 자세히 살펴보면 다음과 같다.

일반 아동들이 무관련 조건에서보다 관련 조건에서 빠른 반응 시간을 보인 것은 이들이 관련 조건의 유도 문장을 읽으면서 실시 간으로 관련된 도구를 추론하였다는 것을 의미한다. 즉, 추론을 통 해 관련된 도구 단어가 이미 활성화되어 있는 상태에서 목표 단어 로 그와 일치하는 도구 단어를 보았기 때문에 그 목표 단어가 단어 임을 판단하는데 시간이 단축되었을 것이다. 이는 성인을 대상으 로 도구 추론과 관련하여 어휘판단과제를 실시하였을 때 온라인 상에서 도구 추론이 생성된다는 결과를 얻은 Lee 등(1997)의 연구 와 맥을 같이 하며, 본 연구 결과로 보아 읽기 이해에 어려움이 없는 학령기 아동들 역시 성인과 마찬가지로 글을 읽는 중에 실시간으로 도구추론이 가능하다는 것을 알 수 있다.

이에 반해, 읽기이해부진 아동들이 관련 조건과 무관련 조건에 서 반응시간의 차이가 없었다는 것은 이들이 관련 조건에서 제시 된 유도 문장을 읽으면서도 실시간으로 그 도구를 추론하지 못하 였거나 그 관련 도구 단어가 약하게 활성화되어 관련된 목표 단어 가 제시되었을 때 반응시간을 단축하는데 도움을 받지 못한 것으 로 해석할 수 있다. 이러한 결과의 원인으로는 크게 두 가지를 고려 해 볼 수 있다. 첫째, 선행연구들에서 보면 읽기이해부진 아동들이 언어성 작업기억에 결함이 있는 것으로 보고되고 있다(Cain \& Oakhill, 2007; Jeong, 2009). 개인마다 작업기억의 용량이 제한되어 있기 때문에 연속적으로 제공되는 정보를 처리하기 위해서는 자원을 적 절히 배분하여 처리의 효율성을 확보하는 것이 중요하다. 그러나 본 연구에서 읽기이해부진 아동들은 유도 문장을 읽으면서 문자적 인 정보를 처리하고 기억하는 데 대부분의 자원을 사용하였기 때 문에 그와 동시에 직접적으로 언급되어 있지 않은 관련 정보를 추 론하는 데는 한계가 있었을 것이다. 이는 작업기억의 개인차가 도 구 추론 생성에 영향을 주었다는 선행연구 결과에 비추어 보아 가 
능한 설명이다(Kim \& Yoo, 2001). 둘째, 읽기이해부진 아동의 의미 처리 특성과 관련지어 생각해볼 수 있다. 의미 연결망 모델(semantic network model)에 따르면, 어휘들은 그 관련 정도에 따라 그물 망처럼 연결되어 심성어휘집(lexicon)에 저장되어 있기 때문에 하 나의 어휘가 강하게 활성화되면 강도의 차이가 있겠지만 그와 연결 되어 있는 다른 어휘들이 동시에 활성화된다고 보았다(Collins \& Loftus, 1975). 그러나 어휘판단과제를 사용하여 읽기이해부진 아 동들의 의미 처리 특성을 살펴본 연구들에서 보면, 읽기이해부진 아동들이 일반 아동들에 비해 어휘판단 속도가 느리고(Choi \& Hwang, 2010), 범주적으로 연관된 단어들을 의미적으로 처리하는 데도 어려움이 있다고 하였다(Nation \& Snowling, 1999). 결국 읽 기이해부진 아동들은 의미 연결망이 약하게 조직되어 있어 의미 처리 효율성이 낮기 때문에 유도 문장에 포함된 도구 추론 단서가 되는 단어들을 보고도 관련된 도구 어휘를 활성화시키는 데 실패 했을수 있다.

본 연구에서 실시한 어휘판단과제는 실시간으로 처리되는 추론 능력을 알아보기 위하여 아동들에게 가능한 빠르게 유도 문장과 목표 단어를 읽고 반응하도록 요구하였다. 일반적으로 신속한 읽기 가 요구되면 추론 생성이 줄어들기 때문에(Jo \& Lee, 1997), 시간을 충분히 활용하여 문장을 읽거나 또는 문장을 읽은 후에 도구 추론 관련 질문을 받았을 때는 어려움이 없었을 읽기이해부진 아동들 도 본 연구에서는 일반 아동들에 비해 저조한 수행을 보였을 것이 다. 일반적으로 학령기 아동들은 많은 양의 글을 읽어야 하거나 시 간의 제약 속에서 글을 읽어야 하는 경우에 흔히 놓이게 된다. 일반 아동들이라면 이 같은 상황에서도 문자 정보 외에 관련 정보들까 지 추론하면서 정보를 보다 풍부하게 활용하여 읽은 내용을 이해 하겠지만 읽기이해부진 아동들은 읽은 정보들을 처리하는 데 급 급하여 관련 정보들을 실시간으로 추론하는 데에는 한계가 있을 것으로 보인다. 결국 읽기이해부진 아동의 이 같은 읽기 이해 특성 은 더 나아가서 읽은 내용을 기억하고 학습하는 데에도 부정적인 영향을 미칠 수 있을 것이다(Jo et al., 2003; Stein et al., 1982).

읽기 이해는 자동적이며 내재적으로 일어나기 때문에(Jo, et al., 2003) 아동들이 글을 읽는 중에 정보를 어떻게 처리하는지를 밝히 는 것은 쉽지 않은 일이다. 이 때문에 아동들의 읽기 이해 및 추론 특성을 밝히고자 했던 대부분의 연구들이 글을 읽은 후에 추론 질 문을 하고 아동들이 이에 답하는 방식을 사용하였다(Yoo, 2017; Jeong, 2009). 그러나 본 연구에서는 읽기 과정에서 실시간 추론이 일어나는지를 알아봄으로써 읽기이해부진 아동들이 읽기 이해에 어려움을 보이는 원인을 밝히고자 했다는 점에서 의의가 있겠다. 이후 같은 연구 방법을 사용하여 다양한 추론 능력을 평가한다면
본 연구 결과를 확고히 하는 데 도움이 되리라 생각된다.

\section{REFERENCES}

Bowyer-Crane, C., \& Snowling, M. J. (2005). Assessing children's inference generation: what do tests of reading comprehension measure? British Journal of Education Psychology, 75, 189-201.

Cain, K., \& Oakhill, J. (2007). Reading comprehension difficulties: correlates, causes, and consequences. In K. Cain \& J. Oakhill (Eds.), Children's comprehension problems in oral and written language (pp. 41-75). New York, NY: The Guilford Press.

Catts, H. W., Adlof, S. M., \& Weismer, S. E. (2006). Language deficits in poor comprehenders: a case for the simple view of reading. Journal of Speech Language and Hearing Research, 49, 278-293.

Choi, K. S., \& Hwang, M. (2010). Semantic processing in children with poor reading comprehension: semantic priming effect during word reading. Korean Journal of Communication \& Disorders, 15, 168-176.

Collins, A. M., \& Loftus, E. F. (1975). A spreading activation theory of semantic processing. Psychological Review, 82, 407-428.

Jang, H. S., \& Lee, E. J. (2016). Reading comprehension of narrative text in poor comprehenders of 5th grade by reading methods. Journal of Special Children Education, 50, 159-176.

Jeong, M. (2009). The predictors of poor comprehenders' reading comprehension in 3 to 6 grades (Doctoral dissertation). Dankook University, Yongin, Korea.

Jeong, M. (2013). The predictors of poor comprehenders' reading comprehension in 3 to 6 grades. The Korea Journal of Learning Disabilities, 10, 79103.

Jo, H. J., \& Lee, J. H. (1997). Text comprehension and inference process: type and character of inference. In J. M. Lee \& J. H. Lee (Eds.), Language and cognition (pp. 275-309). Seoul: Hakjisa.

Jo, M. H., Lee, J. M., Kim, J. O., Shin, H. J., Lee, K. O., Do, K. S., ... \& Jung, H. S. (2003). Psychology of language. Seoul: Hakjisa.

Kim, K. H. (2003). Grade level vocabulary list. Seoul: Pakijung.

Kim, S. I., \& Yoo, H. J. (2001). Individual differences in instrument inference: a comparison of lexical decision task and picture naming task. Korean Journal of Experimental and Cognitive Psychology, 13, 307-321.

Kwak, K. C., Park, H. W., \& Kim, C. T. (2001). Korean Wechsler intelligence scale for children-III (K-WISC-III). Seoul: Seoul Special Education Publishing Co. 
Lee, J. H., \& Lee, J. M. (1999). On-line generation of elaborative inference: predictive inference. Korean Journal of Experimental and Cognitive Psychology, 11, 261-276.

Lee, J. M., \& Lee, J. H. (1997). A psychological process of comprehension. In J. M. Lee \& J. H. Lee (Eds.), Language and cognition (pp. 79-118). Seoul: Hakjisa.

Lee, J. M., Lee, J. H., Kim, S. I., \& Lee, K. H. (1997). Does instrument inference occur on-line during reading? Korean Journal of Experimental and Cognitive Psychology, 9, 75-97.

Lucas, M. M., Tanenhaus, M. K., \& Carlson, G. N. (1990). Levels of representation in the interpretation of anaphoric reference and instrument inference. Memory \& Cognition, 18, 611-631.

Nation, K., \& Snowling, M. J. (1999). Developmental differences in sensitivity to semantic relations among good and poor comprehenders: evidence from semantic priming. Cognition, 7, 1-13.

National Institute of Korean Language. (2005). Investigation on the frequency of the modern Korean language 2. Seoul: Author.

Paris, S., \& Lindauer, B. (1976). The role of inference in children's comprehension and memory for sentences. Cognitive Psychology, 8, 217-227.

Park, G., Kim, G., Song, Y., Jung, D., \& Jung, I. (2008). Korea Institute for Special Education-Basic Academic Achievement Test (KISE-BATT). Ansan; Korea Institute for Special Education.

Stein, B. S., Bransford, J. D., Franks, J. J., Owings, R. A., Vye, N. J., \& McGraw, W. (1982). Differences in the precision of self-generated elaborations. Journal of Experimental Psychology: General, 111, 399-405.

Yoo, K. J. (2017). Characteristics of inference and error in 4-6 grade students with reading comprehension difficulties (Master's thesis). Catholic University of Pusan, Busan, Korea. 
Appendix 1. 조건별 유도 문장과 목표 단어 예시

\begin{tabular}{llc}
\hline 조건 & \multicolumn{1}{c}{ 유도 문장 } & 목표 단어 \\
\hline 관련 & 할머니가 과일을 씻어서 껍질을 깎았다. & 칼 \\
무관련 & & 풀 \\
관련 & 연아가 스케치북을 펴서 색종이를 붙였다. & 칼 \\
무관련 & & 풀 \\
관련 & 철수가 밖으로 나와 몸의 물기를 닦았다. & 수건 \\
무관련 & & 망치 \\
관련 & 선생님이 교실에 들어와 벽에 못을 박았다. & 망치 \\
무관련 & & 수건 \\
채움 & 시연이가 방에 들어와서 모자를 걸었다. & 걈 \\
채움 & 삼촌이 건물 앞에 서서 사진을 찍었다. & 먼앨 \\
\hline
\end{tabular}




\section{국문초록}

\section{읽기이해부진 아동의 정교화 추론 특성: 도구 추론을 중심으로 \\ 박예슬 + 황민아 $\cdot$ 고선희 ${ }^{3}$ \\ '단국대학교 특수교육대학원, ${ }^{2}$ 단국대학교 특수교육과, ${ }^{3 ㄷ ㅏ ㄴ ㄱ ㅜ ㄱ ㄷ ㅐ ㅎ ㅏ ㄱ ㄱ ㅛ ~ ㄷ ㅐ ㅎ ㅏ ㄱ ㅇ ㅝ ㄴ ~ ㅇ ㅓ ㄴ ㅇ ㅓ ㅂ ㅕ ㅇ ㄹ ㅣ ㅎ ㅏ ㄱ ㄱ ㅘ ~}$}

배경 및 목적: 정교화 추론은 글을 읽는 과정에서 글의 내용과 읽는 사람의 지식을 통합하는 것으로 이는 글의 표상을 더욱 정교하게 함으로써 글의 이해를 촉진하고, 정보를 기억하고 학습하는 데 도움을 준다. 본 연구에서는 읽기이해부진 아동을 대상으로 정교화 추 론 중 도구 추론을 중심으로 그 처리 특성을 알아보고자 하였다. 방법: 본 연구는 초등학교 3-6학년 읽기이해부진 아동 15명과 일반 아 동 15 명을 대상으로 하였고, 아동들에게 특정 도구가 연상되는 유도 문장을 읽도록 한 후에 제시되는 글자가 단어인지 아닌지를 판단 하도록 하였다. 이때 유도 문장 후에 제시되는 글자는 유도 문장과 관련된 도구 단어가 제시되는 조건과 관련이 없는 도구 단어가 제시 되는 조건으로 나뉘며 각각의 조건에 대한 반응시간을 측정하였다. 결과: 읽기이해부진 아동은 관련 조건과 무관련 조건 간 반응시간 에 차이가 없었던 데 반해 일반 아동은 무관련 조건에서보다 관련 조건에서 그 반응시간이 빠른 것으로 나타났다. 논의 및 결론: 읽기 이해부진 아동은 일반 아동과 달리 도구가 내현화된 문장을 읽으면서 실시간으로 관련 도구를 추론하는 데 어려움을 보였다. 이는 읽 기이해부진 아동의 경우 글을 읽는 과정에서 사실적인 정보를 파악하기 위해 대부분의 자원을 할당하여 직접적으로 언급되어 있지 않 은 정보를 부가적으로 처리하는 데는 제한이 있는 것으로 해석할 수 있다.

핵심어: 읽기이해부진 아동, 도구 추론, 어휘판단과제

\section{참고문헌}

곽금주, 박혜원, 김청택(2001). 한국 웩슬러 아동 지능검사-III (Korean Wechsler Intelligence Scale for Children-III). 서울: 도서출판특수교육. 국립국어원(2005). 현대 국어 사용 빈도 조사2. 서울: 국립국어원.

김광해(2003). 등급별 국어 교육용 어휘. 서울: 박이정.

김성일, 유현주(2001). 도구추론의 온라인 생성과정에서의 읽기범위 개인차 효과: 어휘판단과제와 그림명명과제의 비교. 한국심리학회지: 실험 및 인

지, 13,307-321.

박경숙, 김계옥, 송영준, 정동영, 정인숙(2008). 기초학력검사(Korea Institute for Special Education-Basic Academic Achievement Test, KISE-

BATT). 안산: 국립특수교육원.

유경진(2017). 초등 고학년 읽기이해부진 아동의 추론유형과오류유형에 따른 추론능력. 부산가톨릭대학교 대학원 석사학위논문.

이재호, 이정모(1999). 정교화추론의 온라인 생성 과정: 예견 추론. 한국심리학회지: 실험 및 인지, 11, 261-276.

이정모, 이재호(1997). 글 이해의 심리적 과정. 인지심리학의 제문제 II: 언어와 인지(이정모, 이재호 편). 서울: 학지사.

이정모, 이재호, 김성일, 이건효(1997). 도구추론의 온라인 생성 과정. 한국심리학회지: 실험 및 인지, 9, 75-97.

장현숙, 이은주(2016). 읽기방식에 따른 초등학교 5 학년 읽기이해 부진학생의 이야기 글 이해능력. 특수교육학연구, 50, 159-176.

정미란(2009). 초등학교 3-6학년 읽기이해 부진학생의 읽기이해력 예측 변인 탐색. 단국대학교 대학원 박사학위논문.

정미란(2013). 초등학교 3-6학년 읽기이해부진학생의 읽기이해력 예측변인 탐색. 학습장애연구, 10, 79-103.

조명한, 이정모, 김정오, 신현정, 이광오, 도경수, 이양, 이현진, 김영진, 김소영, 고성룡, 정혜선(2003). 언어심리학. 서울: 학지사.

조혜자, 이재호(1997). 글이해와추론과정: 추론의 유형과특성. 인지심리학의 제문제 II: 언어와 인지(이정모, 이재호 편). 서울: 학지사.

최경순, 황민아(2010). 읽기이해부진아동의 의미 처리 특성: 의미점화효과. 언어청각장애연구, 15, 168-176. 